\title{
Arte e vida no pensamento de Nietzsche
}

\author{
Rosa Maria Dias*
}

\begin{abstract}
Resumo: o presente artigo pretende analisar a relação arte e vida no pensamento de Nietzsche a partir de duas afirmações, uma de $O$ nascimento da tragédia e a outra de $A$ gaia ciência. No primeiro caso, toma-se como ponto de partida e afirmação de que só como fenômeno estético a vida aparece justificada, mostrando como a relação entre o apolíneo e o dionisíaco, como impulsos naturais e artísticos, conseguem justificar os problemas da existência são ultrapassados. No segundo caso, trata-se de compreender a relação entre arte e vida de duas formas: a arte de se pôr em cena frente a si mesmo e a arte de alguém se tornar o que é.
\end{abstract}

Palavras-chave: arte - vida - estética

Na perspectiva da relação arte e vida no pensamento de Nietzsche, explicitaremos sua concepção de vida como obra de arte. Guiar-nos-emos por duas afirmações: uma se encontra em $O$ nascimento da tragédia e a outra, em A gaia ciência. Em O nascimento da tragédia, a afirmação está expressa da seguinte maneira: "Só como fenômeno estético, a existência e o mundo aparecem eternamente justificados". (GT/NT, Ensaio de autocrítica 5, KSA 1.17). Em $A$ gaia ciência, ela reaparece com algumas modificações: "Como fenômeno estético, a existência é sempre, para nós, suportável ainda" (FW/GC 107, KSA 3.464).

\footnotetext{
* Professora da Universidade Estadual do Rio de Janeiro (UERJ), Rio de Janeiro, Brasil. E-mail: r.maria.dias@gmail.com
} 
Iniciamos pelo $O$ nascimento da tragédia. Quatorze anos após a primeira edição desse livro, Nietzsche acrescenta um prefácio a que denominou "Ensaio de autocrítica". Revendo o que fizera em $O$ nascimento da tragédia, revela ter ousado pensar a arte na perspectiva da vida. A questão metafísica - "que é a arte?" - coincide com a questão existencial - "qual o sentido da vida?" A vida como propósito da arte, a arte como necessária proteção da vida, a vida só se justificando como fenômeno estético, constituem praticamente um leitmotiv que acompanha todas as questões fundamentais do livro.

É preciso salientar que vida e arte são tratadas em $O$ nascimento da tragédia, principalmente, na perspectiva da tragédia grega e a partir do que Nietzsche chama de "impulsos artísticos da natureza" - apolíneo e dionisíaco. Justifica-se, assim, que o ponto mais importante da estética nietzschiana do seu primeiro livro é o desenvolvimento dos aspectos apolíneo e dionisíaco na arte grega, considerados como impulsos antagônicos, como duas faculdades fundamentais do homem: a imaginação figurativa, que produz as artes da imagem (a escultura, a pintura e parte da poesia), e a potência emocional, que encontra sua voz na linguagem musical. Cada um desses impulsos manifesta-se na vida humana por meio de dois estados fisiológicos, o sonho e a embriaguez, que se opõem como o apolíneo e o dionisíaco. O sonho e a embriaguez são condições necessárias para que a arte se produza; por isso, o artista, sem entrar em um desses estados, não pode criar.

O sonho é a força artística que se projeta em imagens e produz o cenário das formas e figuras. Apolo é o nome grego para a faculdade de sonhar; é o princípio da luz, que faz surgir o mundo a partir do caos originário; é o princípio ordenador que, tendo domado as forças cegas da natureza, submete-as a uma regra. Símbolo de toda aparência, de toda energia plástica, que se expressa em formas individuais, Apolo é o magnífico quadro divino do princípio de individuação e a mais bela expressão do repouso do homem em seu invólucro de individualidade. Dá forma às coisas, delimitando-as com contornos precisos, fixando seu caráter distintivo e determinando, 
no conjunto, sua função, seu sentido individual. Modelando o movimento de todo elemento vital, imprimindo a cada um a cadência - a forma do tempo -, ele impõe ao devir uma lei, uma medida. É também o deus da serenidade que, tendo superado o terror instintivo em face da vida, domina-a com um olhar lúcido e sereno.

Já a embriaguez é o estado que destrói, despedaça, abole o finito e o individual. Nela, desfazem-se os laços do princípio de individuação, rasga-se o véu das ilusões para deixar aparecer uma realidade mais fundamental: a união do homem com a natureza.

Sob o mundo das aparências, das formas, da beleza, da justa medida, está o espaço de Dioniso - o nome grego para o êxtase. Dioniso é o deus do caos, da desmesura, da deformidade, da noite criadora do som; é o deus da música, mãe de todas as artes. Nascido da fome e da dor, perseguido e dilacerado pelos deuses hostis, Dioniso renasce a cada primavera e aí cria e espalha a alegria.

Despertadas as emoções dionisíacas, o homem, em êxtase, sente que todas as barreiras entre ele e os outros homens estão rompidas, e que todas as formas voltam a ser reabsorvidas pela unidade mais originária e fundamental - o uno primordial -, na qual só existe lugar para a intensidade. Nesse mundo das emoções inconscientes, que abole a subjetividade, o homem perde a consciência de si e se vê, ao mesmo tempo, no mundo da harmonia e da desarmonia, da consonância e da dissonância, do prazer e da dor, da construção e da destruição, da vida e da morte.

O mundo fenomênico, como resultado desse movimento do querer, traz em si as marcas da dor, do despedaçamento do uno primordial, e, para libertar-se dessa dor, faz um segundo movimento, desta vez, estético, reproduzindo o movimento inicial que a vontade realizou em direção à aparência. Deste último, emana a aparência da aparência ou a bela aparência do sonho, um bálsamo para o querer, um remédio para libertá-lo momentaneamente da dor pelo seu desmembramento em indivíduos.

É dessa maneira que Nietzsche, no capítulo 4 de $O$ nascimento da tragédia, explicita o processo transfigurador que a natureza 
artista realiza, por meio do sonho, para criar a bela aparência. Esse não é o mais fundamental estado fisiológico pelo qual a natureza realiza seus impulsos artísticos. O mais essencial é o da embriaguez.

Ao apresentar sua "metafísica de artista", Nietzsche, no primeiro momento de sua análise, não faz menção ao artista humano. Apolíneo e dionisíaco são impulsos artísticos que emergem do seio da natureza, independentemente da mediação do artista. A perfeição do mundo dos sonhos existe sem que seja necessária a cultura artística do indivíduo, e a realidade da embriaguez existe, sem levar em conta o próprio indivíduo, já que se encontra aniquilado, embora redimido num sentimento místico de unidade.

Para que a arte se torne uma atividade do ser humano, é preciso que o indivíduo dê forma ao sonho e à embriaguez. E como isso se fará? Pela imitação. $\mathrm{O}$ artista é um imitador que, em estado lúdico, joga com o sonho ou com a embriaguez — ou, no caso do artista trágico, com ambos ao mesmo tempo. Essa imitação, porém, não deve ser entendida como reprodução ou cópia da natureza, mas sim como imitação de um processo que a natureza realiza para criar ou reproduzir as aparências: "A obra de arte e o indivíduo são uma repetição do processo originário de onde surgiu o mundo, de certa maneira, um anel de onda na onda" (Nachlass/FP 1869-1872, 7[117], KSA 7.165).

Para explicar o jogo da arte com os sonhos, Nietzsche, em $A$ visão dionisíaca do mundo, estabelece a seguinte diferença: enquanto o homem que sonha joga com a realidade, com a vigília, o artista joga com o sonho. A bela aparência do mundo dos sonhos é condição prévia de toda arte da imagem - seja pintura, seja escultura, seja poesia épica.

Enquanto, no estado apolíneo, o homem joga com a realidade, no estado dionisíaco, ou de embriaguez, ele joga com a vontade ou com a própria natureza que nele se revela. Nesse estado de emoção, o artista dionisíaco é levado ao paroxismo de suas faculdades simbólicas; a natureza o força a exprimir-se, a dominar 
o caos da vontade e a criar um novo mundo de símbolos onde se encontram a dança e a música.

Ante o perigo que corria o povo helênico de sucumbir à destruição, a vontade helênica, para contemplar a si mesma, para glorificar-se e seduzir os gregos a continuar vivendo, põe-se diante de um espelho transfigurador: uma tela de formas luminosas e brilhantes, feita nos sonhos, e que apresenta, por assim dizer, a imagem dos deuses olímpicos, belos e perfeitos, para que os gregos pudessem nela se mirar e, invertendo a sabedoria de Sileno, poderem dizer: "A pior de todas as coisas é morrer logo; a segunda pior é simplesmente morrer um dia." (GT/NT 3, KSA 1.14).

A legitimação da existência por meio dessas imagens apolíneas se dá, em primeiro lugar, pelo reflexo que elas projetam na vida cotidiana dos gregos; em segundo, pelo fato de trazer uma interpretação da existência que lhes permite uma liberação da negatividade do cotidiano. A arte apolínea coloca as imagens, especialmente as figuras dos deuses, ao lado da realidade da natureza, para que eles possam ultrapassar a negatividade de cada dia através de uma visão exuberante.

Nietzsche apresenta a arte apolínea como legitimadora da existência dos gregos, embora reconheça que essa solução seja ainda superficial, pois, a cada manifestação embriagadora, rompia-se o invólucro de individuação, o sustentáculo da serenidade, e os gregos se viam mergulhados no devir da vontade, prontos para nela desaparecerem. No esquecimento de si, o dionisíaco celebra sua reunião com outros homens e com a natureza, e esta se regozija com o seu filho perdido. Contudo, esse dionisíaco também experimenta a terrível destruição do abismo, que nada mais é do que a experimentação da desmesura, do excesso, da transgressão, que gera um imenso prazer. $\mathrm{O}$ perigo de negação da existência ocorre quando ele retorna à consciência, depois de ter fitado o absurdo da existência. O perigo é o pessimismo da sabedoria de Sileno. Os artistas dionisíacos, imitando a embriaguez, criam uma forma de legitimar a existência de um modo mais duradouro do que aquela 
que se tornou possível com a transfiguração apolínea: concebem a tragédia, que tem o poder natural de cura contra o impulso dionisíaco bárbaro e que destrói todos os valores gregos de civilização. A tragédia proporciona ao grego a possibilidade de experimentar o dionisíaco e voltar para o dia a dia, sem a visão pessimista da vida. A revelação levada a cabo pela tragédia traz consolo. Expõe o abismo, mostra-o e, ao mesmo tempo, protege, salva, cura mesmo as consequências destrutivas dessa exposição. Traz de volta o grego sofredor, conforta-o, proporciona-lhe a possibilidade de transformar o horrível em sublime.

Entretanto, como isso se dá? Essa é a questão a que Nietzsche pretende responder com o efeito trágico. Na tragédia grega, na arte da reconciliação do apolíneo e do dionisíaco, a destruição do herói trágico traz alegria. Ele é negado para nos convencer do eterno prazer do existir, pois, com sua aniquilação, fica restaurada a unidade originária - a vida eterna da vontade. Nesse momento de êxtase, a luta, a dor, a destruição dos fenômenos aparecem necessárias para nós porque deixam entrever algo de mais profundo que transcende qualquer herói individual: o eterno vivente criador, eternamente lançado à existência. A arte a favor da vida - eis a chave do pensamento de Nietzsche. A arte transfigura o ser existente, mas só a tragédia exprime a crença na eternidade da vida. $\mathrm{O}$ espírito trágico só pode ser explicado em termos musicais. Só a música produz uma réplica do uno primordial; só ela transmite a certeza de que existe um prazer superior para além do mundo dos fenômenos. Todavia, sem o recurso da imagem, a música, penetrando no mais fundo segredo da vida, é puramente dor primordial e eco dessa dor. Tem o poder de reconduzir os ouvintes à natureza, ao estado de prazer eterno onde eles sacrificam sua individualidade por um sentimento irresistível de identificação com o uno primordial.

Nietzsche descreve o poder da música como algo cheio de perigo, capaz de acarretar a destruição do indivíduo. Para que o homem possa ouvir a música - sinfonia da afirmação eterna - e sentir-se tocado pelo seu poder sem aniquilar-se, Apolo vem em 
seu socorro, restaurando sua individualidade quase aniquilada, traduzindo a sabedoria dionisíaca em imagens apolíneas. $\mathrm{O}$ mito e o herói trágicos, colocados junto à música, fazem o papel de um Titã poderoso que toma, sobre seus ombros, o mundo dionisíaco para dele nos livrar.

Assim, os espectadores, embora forçados a testemunhar a catástrofe trágica, não se aterrorizam; ao contrário, têm uma "consolação metafísica" que os arranca, momentaneamente, do alvoroço da mudança das figuras. Por breve momento, a vida, no fundo das coisas, a despeito da mudança dos fenômenos, é indestrutivelmente poderosa e alegre. O consolo metafísico aparece corporificado no coro de sátiros - seres naturais que vivem inextinguivelmente por trás de toda a civilização e que, a despeito da mudança das gerações e da história dos povos, permanecem os mesmos. Com esse coro, consola-se o heleno profundo, o único igualmente apto para as dores mais suaves e mais cruéis, que viu o horror da natureza e corre perigo de aspirar a uma negação budista da existência, que penetrou com olhar afiado até o fundo da terrível tendência ao aniquilamento, o qual move a chamada "história universal".

A arte trágica demonstra, assim, uma notável capacidade alquímica de transmudar o estado de náusea, negador da vontade, em afirmação, de modo que esse horror possa ser experimentado não como um horror, mas como algo sublime, e esse absurdo possa ser vivenciado não como absurdo, mas como cômico.

Explicitada a compreensão de Nietzsche da relação arte e vida em $O$ nascimento da tragédia, passemos, agora, para $A$ gaia ciência, onde ele apresenta duas saídas artísticas para fazer frente ao sofrimento de estar diante de uma vida sem sentido e sem o consolo de Deus. Por sugestão de Julien Young, chamaremos uma de apolínea e a outra, de dionisíaca. Caracterizaremos a primeira como arte de poder ver a si mesmo à distância ou "a arte de se pôr em cena frente a si mesmo", e a segunda, como a arte de "como alguém se torna o que é" - fórmula máxima da afirmação total da existência. Ambas as saídas utilizam-se de técnicas artísticas. Antes de esclarecê-las, 
é bom lembrar que, ao dar os nomes apolínea ou dionisíaca a essas atividades, não estamos retomando a "metafísica de artista" de Nietzsche de $O$ nascimento da tragédia.

A saída apolínea imita a técnica artística do teatro, particularmente, a da distância artística. Dois importantes aforismos de $A$ gaia ciência podem elucidar essa estratégia: o aforismo 78, "Pelo que deveríamos ser gratos", e o 299, “O que devemos aprender como os artistas".

A arte de ver a si mesmo e o mundo através de filtros coloridos, de pôr a si mesmo e as coisas em plano geral e, para usar uma expressão cinematográfica, de se ver como herói que conquistou seus próprios temores, que se identificou com o ritmo e o fluxo da vida e consigo mesmo, é uma forma de enfrentar o sofrimento humano, quando lhe foram cortadas as raízes metafísicas. A outra maneira é a dionisíaca, que faz pensar nas técnicas da literatura na construção de um personagem. Como observa Julien Young em seu livro Nietzsche's philosophy of art, essa saída é superior à apolínea; não é concebida para convalescentes, mas sim para aqueles que, diante da vida e em qualquer um de seus aspectos, podem afirmá-la inteiramente. A essa ação dionisíaca, Nietzsche dá o nome da arte de "Como alguém se torna o que é" (Wie man wird, was man ist).

Antecipando o percurso que faremos para elucidar a fórmula "como alguém se torna o que é", pode-se dizer que a leitura completa e sem preconceito do imperativo ensina não a metamorfose pela metamorfose, e sim a marcha lenta em direção a si mesmo, ao estado dionisíaco em que o homem se vê desembaraçado de todas as negações restritivas, onde possa pronunciar um sim incondicional a si mesmo e à vida. Assim, o homem deve tornar-se mestre de si mesmo pouco a pouco, e só chegar a esse tornar-se com a paciência de construir, durante longos anos, sua própria escultura - sem, com isso, poder dizer um dia que está completo e plenamente realizado.

Em Humano, demasiado humano, Nietzsche escreve que são raros aqueles que possuem a paciência e a energia suficientes para dar forma às suas virtudes. Numa humanidade altamente 
desenvolvida como a de hoje, cada um tem possibilidade de desenvolver vários talentos. Poucos, no entanto, possuem tenacidade, perseverança, para exercer esse talento em obras e ações. Também Zaratustra condena, sem piedade, os fracos, os preguiçosos que, ao nascerem, já desejam morrer.

A educação moderna não permite a lenta maturação dos jovens. Por isso, o ser humano está longe de ser mestre em sua arte de viver: precisaria vencer o grande tédio, necessitaria de muito suor, até conseguir achar suas cores, seu pincel, sua tela.

Em Schopenhauer como educador (1874), aparece, pela primeira vez na obra de Nietzsche, uma fórmula semelhante ao "torna-te o que tu és". Surge como imperativo de liberação: "Sê tu mesmo!" "O homem que não quer pertencer à massa necessita apenas deixar de ser indulgente consigo mesmo; seguir sua própria consciência que lhe grita: "Sê tu mesmo!". Tu não és nada disso que agora fazes, pensas, ambicionas. É imperativo que acentua a solidão do ser humano, que não pode mais confiar na religião, nem na sociedade, nem no Estado para encontrar seu próprio caminho. Essa Terceira Extemporânea não se dirige aos que pretendem relaxar - destina-se aos que têm algo para decidir acerca de sua vida e de sua atitude diante da cultura.

No primeiro parágrafo de Schopenhauer como educador, Nietzsche relata a seguinte passagem: perguntaram a um viajante que havia percorrido muitos países e conhecido muitos povos qual a qualidade que mais encontrara nos homens. Eis sua resposta: "Uma propensão à preguiça" (SE/ Co. Ext. III 1, KSA 1.337). Por toda parte, encontrara homens entediados, escondendo-se atrás dos costumes e das opiniões alheias. Por preguiça e temor do próximo, comportam-se de acordo com as convenções e seguem a moda do rebanho. Que motivo têm para adotar sempre as opiniões e as apreciações de valor de seu semelhante? Em uma palavra, o hábito. Desde a infância, convivem com as apreciações de valores de seus avós. São guiados por esses juízos adquiridos e raramente pensam 
na aprendizagem. Desde crianças, são albergues abertos a tudo e, como todo mundo, acreditam que a maior virtude é estar conforme as opiniões de todos.

No entanto, para que os homens se desprendam e se defendam das virtudes do rebanho, é necessário que engulam a seguinte verdade, como um remédio amargo: a primeira virtude do homem é ousar ser ele mesmo. É preciso triunfar sobre si mesmo, isto é, sobre a natureza que lhe foi inculcada e o tornou inepto para a vida. Para Nietzsche, não há espetáculo mais hediondo do que ver um homem que se despojou do seu gênio, do seu ser criador e inventivo. Falta-lhe medula. Só tem fachada. Assemelha-se a um fantasma da opinião pública.

$\mathrm{O}$ fato de o homem ser uma singularidade e, como todo caso único, não se repetir, deve encorajá-lo a viver segundo sua própria lei e medida. Ele tem de mostrar por que nasceu em determinada época, e não em outra, pois, só desse modo, fará justiça a seu próprio tempo.

$\mathrm{Na}$ interpretação dessa singularidade conclamada por Nietzsche, um contrassenso deve ser evitado. Foi sempre prerrogativa de filósofos e moralistas convidar o ser humano a buscar a sua natureza íntima, a conhecer a si mesmo. Para isso, bastava que o indivíduo se despojasse dos artifícios que cobrem o seu íntimo. Poder-se-ia pensar que, de certa forma, o mesmo se dá com Nietzsche. Entretanto, não se pode aplicar uma leitura metafísica à questão do individualismo em Nietzsche. A crítica da noção de sujeito, de consciência e de "eu" é uma constante em sua obra. Desde os seus primeiros escritos, Nietzsche repudia a ideia espúria de um eu fixo e estável, a qual contribui, em muitos aspectos, para a vida gregária, pois, no fundo, esse "eu" é igual a todos os outros "eus" gregários.

Ele é uma mistificação que deve ser superada, o depositário de todo o ideal burguês, de todo preconceito que recebemos de nossos pais e avós. O "eu" a que Nietzsche se refere é algo que se reinventa, e não uma substância fixa. Assim, para o filósofo, não 
existe um verdadeiro eu, pois ninguém pode estar certo de ter-se despojado de todas as suas máscaras - por trás de cada máscara, há sempre muitas outras máscaras; por trás de cada pele, outras peles.

Assim, o que revela a "lei fundamental de nosso ser" é o conjunto dos objetos que nos preenchem e dominam. É a sucessão dos objetos venerados, isto é, o que temos amado, o que nos atrai, o que nos tem feito felizes, e a comparação que se pode estabelecer entre tais objetos. É isso que revela nossa individualidade.

Contudo, só a direta observação de si mesmo não basta para um ser humano conhecer-se. Para Nietzsche, não é suficiente ser um único homem, embora seja um começo necessário: é preciso passar de uma individualidade a outra, atravessar a existência de numerosos seres. É necessário ver a si mesmo através de uma multidão de olhares, sobretudo, da história, pois o passado continua a fluir dentro de nós em mil ondas; e nós mesmos não somos senão o que a cada instante percebemos desse fluir. "Também aí, quando queremos descer ao rio do que aparentemente é mais nosso e pessoal, vale a afirmação de Heráclito: não se entra duas vezes no mesmo rio" (MA II/HH II 223, KSA 2.477). Para compreender a História, é necessário viajar como o velho Heródoto, visitar povos, em particular, aqueles que passam por selvagens e semisselvagens. E existe ainda uma arte de viajante mais sutil, que consiste em descobrir, em nossa vizinhança, os vestígios do século passado.

Quando não está superdimensionada, a cultura histórica revela-se muito útil à espécie humana. As viagens ao estrangeiro, nos sentidos próprio e figurado, levam-nos a um longo desvio de nós mesmos, ao nosso "verdadeiro eu", que teremos de aprofundar no curso de nossas peregrinações. Desse modo, a cultura histórica aprofunda o cultivo de si e vice-versa. É uma vantagem decisiva a espécie humana poder beneficiar-se das experiências tentadas por outras civilizações e tomar consciência de seu objetivo, que é o de ultrapassar-se e tornar possível a criação de tipos superiores.

Ainda em Humano, demasiado humano, Nietzsche procura enfatizar a responsabilidade que temos pela nossa própria existência; 
daí, o lema liberador "Sê tu mesmo!" continuar a ser aprofundado nesse livro, apesar de, como veremos, ser um texto de ruptura através do qual Nietzsche se põe contra os seus modelos do passado. Um bom complemento para o lema "Sê tu mesmo!" é o aforismo 292 de Humano demasiado humano, no qual Nietzsche exorta o ser humano a ter confiança em sua própria experiência.

Nesse período, Nietzsche proclama a primazia da ciência para ele, sinônimo de método de investigação crítica, cujo objetivo é liberar-nos do mundo metafísico, do sobrenatural e da coisa em si kantiana. Distancia-se não só do que havia revelado no prefácio de $O$ nascimento da tragédia, quando escreve que a arte é "a atividade verdadeiramente metafísica" dessa vida, mas também de sua concepção do dionisíaco e, consequentemente, da ideia de "consolo metafísico" - da possibilidade de se chegar ao âmago da vida através da música, para poder afirmá-la. Nesse momento, tudo isso é, para ele, crença teológica. Não existe nenhum ser primordial para se identificar e sentir, por breves instantes, nenhuma luneta mágica para se olhar diretamente a essência. Também a música não reina mais solitária no reduto das artes, não é mais a "linguagem imediata do sentimento" (MA I/HH 1 215, KSA 2.175). Não é profunda, nem significativa; não fala da "vontade", nem da "coisa em si". É arte que, até nos espíritos livres, faz vibrar as cordas metafísicas. Também em Opiniões e sentenças diversas (1879) e em $O$ andarilho e sua sombra (1880), complementos do segundo volume de Humano, demasiado humano, Nietzsche continua a fazer avaliações críticas à arte, a desmascará-la quando está envolvida em sua áurea metafísica. Entretanto, nesses livros, há outro ponto de vista a partir do qual ele revaloriza a arte. Não se trata mais, certamente, de nenhuma que leve o homem a evadir-se de si mesmo, a buscar o fantástico, o além-mundo, mas da arte de criar-se a si mesmo como obra de arte. O parágrafo 174 de Opiniões e Sentenças diversas, intitulado Contra a arte das obras de arte, marca essa transição.

Desse fragmento, é possível depreender que a arte de embelezar a vida não é uma atividade cosmética, exercida sobre uma 
realidade descolorida e sem graça; não é a arte de esconder, envolvendo com véus a paixão e a miséria dos insatisfeitos. Nietzsche não está aqui reabilitando o apolíneo. Embelezar a vida é sair da posição de criatura contemplativa e adquirir os hábitos e os atributos de criador, ser artista de sua própria existência.

E como fica a arte das obras de arte nessa tarefa de criar a si mesma como obra de arte? Nietzsche não se contrapõe às obras de arte. Opõe-se, sim, em primeiro lugar, à deificação das obras de arte, ao pensamento que, por atribuir todos os privilégios da criação ao gênio, deixa de criar a si mesmo; em segundo lugar, ao desperdício de forças. Somente aqueles que trazem consigo um excedente de forças deveriam a ela se dedicar. É preferível empregar toda a quantidade de forças para criar a si mesmo a despendê-la na arte, e, com isso, pôr à mostra o que não merece ser mostrado. $\mathrm{E}$, ainda, é preferível viver sem as artes, não ter necessidade dessa ou daquela, transformar-se continuamente a si mesmo, a fazer uso dela por horas ou instantes, para afugentar o mal-estar e o tédio. A arte das obras de arte é apenas um "apêndice" da arte de viver, a "sobremesa, e não o prato principal".

O segundo volume de Humano, demasiado humano é, assim, porta-voz de um deslocamento do centro de gravidade da filosofia de Nietzsche sobre a arte - a passagem da reflexão sobre as obras de arte para uma reflexão bem particular: a vida mesma considerada como arte. E, desse modo, Nietzsche diminui ainda mais a separação entre arte e vida, torna-a determinante na construção de belas possibilidades de vida.

Dito isso, podemos deter-nos agora nesta sentença de Nietzsche: "Como fenômeno estético, a existência é sempre, para nós, suportável ainda". Se pensarmos a sequência da frase de $A$ gaia ciência, teremos uma indicação de como Nietzsche tratará a questão. Diz ele: "Por meio da arte, nos são dados olhos e mãos e, sobretudo, boa consciência, para poder fazer de nós mesmos um tal fenômeno" (FW/GC 107, KSA 3.464). Perguntamos: mãos e olhos, para quê? Certamente, não para qualquer atividade, mas para a que permite 
livrarmo-nos do aspecto cruel da existência. É ela uma ação artística, uma atividade de criar a si mesmo como obra de arte, que tem a boa consciência do seu lado, e pode, em alguns momentos, ser contra o costume e, até mesmo, imoral.

Nessa tarefa de se tornar sem cessar o que se é, de ser mestre, poeta e escultor de si mesmo para enfrentar o sofrimento do mundo sem Deus, as técnicas do artista, e principalmente as do poeta e do romancista, podem ser de grande valia, já que elas mostram como é possível escrever para nós um novo papel, um novo personagem com outro caráter. Todo caráter, para Nietzsche, começa por ser um papel - escrever por cima de memórias, caracteres, traços fortemente marcados e ambições profundas, que nos deram forma, uma nova espécie de personalidade superficial que experimenta o mundo com uma leveza fugaz, divinamente não perturbado, divinamente superficial, "por ser profundo". Uma incrível leveza em ser o que é. Aqui acrescenta algo, ali suprime outro tanto, mas, em ambas as vezes, aplica longa prática e trabalho diário. "Aqui o feio que não podia ser retirado é escondido, ali é reinterpretado como sublime" (FW/GC 290, KSA 3.530). Muito do que era vago e resistia a tomar forma foi reservado para ser utilizado mais adiante. Por fim, terminada a obra, é manifesto o modo como o gosto próprio dominou e deu forma, nas coisas grandes e pequenas; se o gosto foi bom ou mau, significa menos do que se pensa - é suficiente que seja um gosto próprio (FW/GC 290, KSA 3.530).

Porém, para ousar ser um si mesmo, é preciso, antes de tudo, uma tarefa: "dar estilo a seu caráter" (FW/GC 290, KSA 3.530), acomodando os vários aspectos de sua própria natureza, inclusive as fraquezas, dispondo-as em uma totalidade aprazível de acordo com um plano artístico. É importante frisar: Nietzsche está mais interessado em um "gosto" próprio do que na qualidade desse gosto. E ainda deixa claro que, para realizá-lo, "deve-se primeiro convencer o corpo" (GD/CI, Incursões de um extemporâneo 47, KSA 6.148). É preciso começar esse planejamento a partir do lugar certo, "não na 'alma' (como pensava a funesta superstição dos 
sacerdotes e semissacerdotes): o lugar certo é o corpo, os gestos, a dieta, a fisiologia, o resto é consequência disso..." (GD/CI, Incursões de um extemporâneo 47, KSA 6.148). Para compreender o que é o homem, é preciso tomar o corpo como guia - é ele o fundamento de toda a vida moral, intelectual e artística.

Então, uma questão apresenta-se: pode-se considerar "tornar-se o que se é" uma tomada de decisão de se modificar, é algo da ordem do livre arbítrio ou de uma decisão da vontade? É possível realmente educar e transformar os impulsos? Podemos educar o corpo, "essa estrutura social de "muitas almas" (JGB/BM 19, KSA 5.31), essa subjetividade orgânica, edifício plural das forças inconscientes?

Para Nietzsche, a crença no livre arbítrio repousa sobre falsas interpretações - é da ordem da mitologia. Em um corpo, os impulsos perseguem seus objetivos, desprezando todas as considerações teóricas. Em todos os esforços conscientes, são sempre os impulsos que estão em atividade, que inspiram nossas teorias e nossa moral. Impossível escapar deles. Em Além do bem e do mal, Nietzsche escreve que "a vontade de superar um afeto é, em última instância, tão somente a vontade de outro ou vários outros afetos" (JGB/BM 117, KSA 5.93). Os impulsos se educam, transformam-se, disciplinam-se, dominam-se entre eles mesmos. Na sua luta interna pela supremacia, cada um deles se sente entravado ou estimulado, lisonjeado pelos outros. Cada um tem sua própria lei de evolução: enquanto um declina, o outro toma posse de um determinado acontecimento. Assim sendo, ao tomarmos o corpo por guia, poderemos reconhecer no ser humano uma pluralidade de seres vivos que lutam ou colaboram entre si. Como diz Zaratustra, "o corpo é uma grande razão, uma multiplicidade com um único sentido, uma guerra e uma paz, um rebanho e um pastor" (Za/ZA I, Dos desprezadores do corpo, KSA 4.39). Ora, só ele pode autossuperar-se; nele se encontra o princípio de toda a hierarquia. Cada impulso animado por uma vontade de potência procura dominar os outros e impor-se como mestre. Qualquer que seja o método empregado 
para combater a violência de um instinto, a decisão, a vontade de combatê-lo resulta de um processo inconsciente. Em toda luta, o essencial escapa-nos, nosso intelecto e nossa pretensa vontade são instrumentos cegos de um impulso que procura por outro para exercer sua potência, efetivar-se, dominar e criar novas interpretações. Isso porque a tendência fundamental da vida é vontade de potência, e o homem, uma pluralidade de vontades de potência.

A decisão de se modificar não é da ordem da consciência; esta, ao contrário, é o último traço que se acrescenta ao organismo quando ele já funciona perfeitamente; é apenas um instrumento a serviço de nossos impulsos. Toda vida consciente, o espírito e a alma, o coração e a bondade trabalham para aperfeiçoar o mais possível as funções animais. Contudo, na busca das condições favoráveis ao desenvolvimento harmonioso, o intelecto exerce um papel que não pode ser negligenciado. Ele não constitui a força motriz, não fixa os objetivos, mas é um instrumento do corpo, e muito precioso - pode contribuir para canalizar a força dos impulsos. A ação de um impulso sobre o outro pode ser reforçada por essa faculdade própria ao homem de buscar inteligentemente os meios apropriados e eficazes de chegar aos fins que ele sente necessário atingir. $\mathrm{O}$ intelecto é, assim, um instrumento de nossos impulsos, e aperfeiçoa-se.

Embora o poder sobre nós mesmos não seja muito grande, ninguém poderá, em virtude de uma simples decisão, modificar-se profundamente em um sentido determinado. É o inconsciente, isto é, o corpo com seus impulsos, que nos conduz. Podemos, sim, cuidar de nossas vidas, evitar certos acontecimentos e certas condições de existência, e tratar de encontrar saídas mais favoráveis ao nosso desenvolvimento. No entanto, não podemos impedir que um impulso, que pede para exercer sua força, examine cada evento do dia para saber como pode utilizá-lo para seus fins.

Frequentemente incriminamos o acaso pelo insucesso de algo que planejamos conscientemente. Com isso, permanecemos com nossa crença no livre arbítrio, alimentamos nossa tendência 
a acreditar que escolhemos livremente, como também aumentamos nossa participação consciente em todo o ocorrido. É sempre "a grande razão" que comanda tudo. A inteligência, a vontade são instrumentos de sua mão. Só o corpo sabe o que quer, é ele quem persegue com tenacidade seu objetivo: o crescimento da potência. Animado por uma vontade de mudança, de crescimento, utiliza o intelecto para se alçar a um nível superior, para se superar sem trégua. Todavia, o ser humano pode educar-se, criar-se, elevar-se. Nietzsche, até o fim de seus dias, atribui um papel importante à educação. Ela lhe dá esperanças para superar a tristeza que o espetáculo da humanidade provoca nele. Ao definir "o homem como um animal ainda não determinado" (JGB/BM 62, KSA 5.81) sabe que o ser humano corre o risco de extraviar-se e degenerar-se, mas, por outro lado, e por causa mesmo dessa maleabilidade da espécie humana, pode educar-se, e sua mudança pode trazer-lhe grandes esperanças. Orientado em direção a algo que o ultrapassa, o ser humano pode fazer surgir novos seres, de tal modo que um tipo de humanidade possa ser superado e ultrapassado.

\begin{abstract}
: this article aims at analyzing the relationship between art and life within Nietzsche's thought in the light of two statements, which have been made in The Birth of Tragedy and in The Gay Science respectively. The first assertion provides us a starting point for the idea that only as an aesthetic phenomenon is life justified, showing why the relationship between Apollonian and Dionysian, as well as between natural and artistic impulses, overcomes the problems of existence. The second assertion leads us to a double comprehension of the relation between life and art: the art of presenting ourselves artistically to ourselves and the art of becoming what one already is.
\end{abstract}

Keywords: art - life - aestethics

Cad. Nietzsche, São Paulo, v.36 n.l, p. 227-244,2015. I $\mathbf{2 4 3}$ 
Dias, R. M.

\section{referências bibliográficas}

NIETZSCHE, F. Sämtliche Werke. Kritische Stuenausgabe. Org. Giorgio Colli e Mazzino Montinari. Berlim; Nova York: Walter de Gruyter, 1988.

. Sämtliche Briefe. Kritische Studienausgabe. Org. Giorgio Colli e Mazzino Montinari. Berlim; Nova York: Walter de Gruyter, 1988.

YOUNG, Julien. Nietzsche's Philosophy of Art. Cambridge: Cambridge University Press, 1992.

Artigo recebido para publicação em 15/10/2014.

Artigo aceito para publicação em 17/12/2014.

244 | Cad. Nietzsche, São Paulo, v.36 n.1, p. 227-244, 2015. 